\title{
Toward the understanding of national culture in the success of non-pharmaceutical technological interventions in mitigating COVID-19 pandemic
}

\author{
Manjul Gupta ${ }^{1}$ (D) Amin Shoja ${ }^{1} \cdot$ Patrick Mikalef $^{2}$
}

Accepted: 22 January 2021 / Published online: 3 February 2021

(c) The Author(s), under exclusive licence to Springer Science+Business Media, LLC part of Springer Nature 2021

\begin{abstract}
This study conceptually explores the relationship between a nation's culture and the success of utilizing various digital technologies to mitigate the spread of a pandemic, such as novel coronavirus (COVID-19). In the absence of a cure or vaccine of COVID-19, the national governments and public health authorities have been aggressively utilizing digital technologies to mitigate the pandemic spread. Given the urgency caused by COVID-19, this study highlights the importance of considering a country's national culture in evaluating the efficacy of a given digital technology, despite how promising or groundbreaking it may sound, in combating the spread of an infectious disease. Relying on the two critical dimensions of national culture, power distance and individualism/collectivism, this study proposes a framework that describes how people from different countries, depending on their prevalent national cultural values, would be receptive (or intolerant) to using government-run technology solutions meant for curbing the pandemic spread.
\end{abstract}

Keywords Coronavirus $\cdot$ COVID-19 $\cdot$ Non-pharmaceutical intervention $\cdot$ Social distancing $\cdot$ Contact tracing $\cdot$ Quarantine $\cdot$ Digital technologies

Manjul Gupta

mgupta@fiu.edu

Amin Shoja

ashoja@fiu.edu

Patrick Mikalef

patrick.mikalef@ntnu.no

1 College of Business, Florida International University, Miami, FL, USA

2 Department of Computer Science, Norwegian University of Science and Technology (NTNU), Trondheim, Norway 


\section{Introduction}

The novel coronavirus (COVID-19) has caused extraordinary challenges for public health systems at the global level (Huang et al. 2020a; Zhu et al. 2020). The World Health Organization (WHO) declared the COVID-19 epidemic a "pandemic" on March 11th, 2020, and called for member states to take urgent actions to protect their citizens from the outbreak (WHO 2020). Admittedly, prior to the COVID-19 virus outbreak, the humanitarian supply chain faced multiple challenges to enhance important aspects of disaster relief operations (Dubey et al. 2020a, b; Akter and Wamba 2019; Balcik et al. 2010; Banomyong et al. 2019; Dubey et al. 2019; Behl and Dutta 2019; Çankaya et al. 2019). This pandemic has unfolded remarkably fast and created a humanitarian crisis by threatening billions of individuals globally, which demands swift disaster relief efforts and humanitarian operations (Ivanov and Dolgui 2020a, b; Queiroz et al. 2020; Anparasan and Lejeune 2019). A report by the Imperial College COVID-19 Response Team predicted that COVID-19 would cause 7 billion infections and 40 million deaths in 2020 alone in the absence of public health interventions (Walker et al. 2020). Such a crisis would disproportionately impact lower socioeconomic groups and forcibly displaced populations (Truelove et al. 2020; Dahab et al. 2020).

Countries were left with no option but resort to using aggressive non-pharmaceutical interventions, such as widespread lockdown, stay-at-home orders, closing of educational institutes and non-essential businesses, and imposed restriction on domestic and international travels. Further, in places where individuals have to be present in the same physical space, the best tool to mitigate the spread of COVID-19 is through social distancing (CDC 2020). Social distancing refers to maintaining a distance of six feet (or more) from others when outside. Though these policy responses have been successful with varying degrees in different countries, these non-pharmaceutical interventions have detrimental consequences on the real economic activities in many industries and financial markets. The economy as a whole contracted significantly (Barro et al. 2020). More than 22 million workers have filed unemployment benefits requests in the U.S. labor market alone during a month of COVID-19 related shutdowns, representing the macroeconomic level impacts of this pandemic (Morath and Chaney 2020). There is no doubt that there is a great deal of uncertainty about several unknown aspects of this crisis, including the most effective viewpoints towards pandemic management and appropriate responses in different countries.

One of the crucial aspects of the national governments' coordinated policies and strategies worldwide is the role of digital technologies. Digital information technologies could be useful in multiple ways, such as tracking, screening for infection, contact tracing, quarantine and self-isolation, and clinical management (Whitelaw et al. 2020). Unprecedented times call for an unprecedented use of technologies. So much so that some countries have been utilizing technology, ranging from mobile phones, mobile payment applications, social media applications, AI-powered surveillance cameras, and drone borne cameras, among others, to not only collecting real-time data on the location of individuals but also to track and restrict the movement of individuals within a monitored/lockdown region. There have also been reports of some countries using security camera footage, credit card records, and GPS data from individuals' cars to track individuals' movements if they were asked to self-isolate, either because they were infected with COVID-19 or came in contact with someone who was infected. For example, in Singapore, the government launched a mobile application that utilizes 
Bluetooth signals to ensure that the infected individuals (and those who came in contact with them) are self-quarantining themselves (Dick 2020).

While different countries are taking diverse technological approaches to combat this pandemic, it is fair to say that there is no one size pandemic-mitigation technological approach that fits all. A technological intervention, such as forcing those infected with COVID-19 to report their physical movements 24/7 using a mobile application that may efficiently work in one country may not necessarily be successful in others. This is because significant political, economic, cultural, and social differences exist between and among countries. Prior research suggests that country-level differences can be best explained by studying cultural differences between countries (Geert. Hofstede 1980). Moreover, a country's national culture can further influence its political, economic, and social environment (Geert. Hofstede 1980; Gelfand et al. 2011).

This study conceptually explores: How does the relationship between a nation's culture and the success of utilizing various digital technologies help mitigate the spread of a pandemic, such as COVID-19? As discussed earlier, there are myriad ways in which countries have been exploiting digital technologies to manage the disease spread. However, without considering the cultural traits that are intrinsic to a country, it is challenging to assess whether a technology, in spite of how promising or groundbreaking it may sound, would be used by its potential users. Over the years, scholars have created models of technology acceptance (Venkatesh et al. 2012) and how national cultural values may affect their acceptance (Gupta et al. 2019); however, the case of COVID19 is different. The government-run non-pharmaceutical technological initiatives are different from what we know in terms of published research on technology acceptance that primarily focuses on employees' use of technology to boost their productivity and/ or creativity (Davis 1989; Srite and Karahanna 2006; Venkatesh et al. 2012). Not only do these non-pharmaceutical technological approaches, if implemented correctly and used by people as intended by their national governments, could potentially save lives, but may also help the economy bounce back. Given the urgency caused by the pandemic, this study highlights the importance of considering a country's national culture in evaluating the efficacy of a given digital technology in combating the spread of an infectious disease.

To do so, we rely on Hofstede's framework of national culture (Geert Hofstede et al. 2010). We specifically focus on its two widely used national cultural dimensions of individualism-collectivism and power distance. Utilizing the available national-level cultural scores on both individualism-collectivism and power distance cultural dimensions in the literature, we propose a $2 \times 2$ framework of countries based on the intersection of high and low degree of collectivism and power distance, resulting into four quadrants where each quadrant represents countries with: (1) high power distance and collectivism, (2) high power distance and individualism, (3) low power distance and individualism, and (4) low power distance and collectivism. Then, we discuss how people from different countries, depending on their prevalent national cultural values, would be receptive (or intolerant) to using digital technologies meant for curbing the pandemic spread.

This paper is structured as follows. First, we discuss the concept of national culture, followed by a section on the use of non-pharmaceutical technological initiatives currently employed around the world. Then, we discuss the link between national culture and the technology use for pandemic mitigation. The paper ends with a discussion section. 


\section{National culture}

The literature on the role of national culture in operations research has been growing; however, due to the breadth of the concept of culture, the research involving culture remains challenging (Gupta and Gupta 2019; Jabbour et al. 2020). The primary challenge pertains to the presence of more than 150 definitions of culture in the literature, yet there is no consensus on one (Kroeber et al. 1952). For example, Hill (2005) describes culture as a system of values and norms shared among a group of individuals. Hofstede (1980) calls culture as "the collective programming of the mind which distinguishes the members of one human group from another" (p. 260). Doney et al. (1998) applied the "national" label to culture to differentiate the character of a society from an "organizational" culture.

Not only there exist countless definitions of culture in the literature, but also crosscultural scholars have presented several frameworks for studying the construct of national culture. For example, Gelfand et al. (2011) developed a construct of national cultural tightness-looseness that measures the strength of societal norms and tolerance of deviant behaviors in a country. Earley and Ang (2003) presented a framework of cultural intelligence that captures an individual's ability to behave appropriately in cross-cultural situations. Hall and Hall (1976) conceptualized culture with respect to the communication context, which is the extent to which a society prefers to use high context messages (less explicit) over low context (highly explicit) messages in everyday communication. The two most cited cultural frameworks in the field are the ones from Hofstede's (1980) and House et al. (2004). Interestingly, Hofstede's definition and framework of national culture remain the most utilized model in the area of cross-cultural business research. There is a near consensus among academics concerning the potential of employing Hofstede's cultural framework to understand a country's culture and differentiate it from another's (George et al. 2018; Gupta et al. 2018; Metters et al. 2010).

Consequently, in this study, we rely on Hofstede's model, which consists of six dimensions of national culture. The initial model consisted of four dimensions- individualism/ collectivism, power distance, uncertainty avoidance, and masculinity/femininity - that were identified from the data collected from IBM employees in 64 countries. The fifth cultural dimension, long/short-term orientation, was added later to the framework based on the cross-cultural work of Michael Bond, a social psychologist, in China (Geert Hofstede and Bond 1988). Hofstede et al. (2010) have recently added indulgence/restraint as the sixth dimension to their model.

Individualism/collectivism measures the extent to which individuals in a nation are affiliated with loosely or tightly-knit social groups. Power distance captures the degree to which the less powerful members of a nation accept and expect that power is distributed unequally. Uncertainty avoidance is the degree to which the members of a nation feel uncomfortable with unpredictability and ambiguity. Masculinity/femininity measures the extent to which individuals in a nation prefer achievement, heroism, assertiveness, and material rewards for success versus cooperation, modesty, caring for others, and quality of life. Long/short-term orientation gauges the extent to which a nation relies on its past while dealing with the present and future challenges. Indulgence/restraint assesses whether society values or suppresses the need for enjoyment and having fun in everyday life.

In this study, we concentrate on the first two cultural dimensions-power distance (PD) and individualism/collectivism (IND/COL) - because of the following reasons. According to a corpus of cross-cultural research, IND/COL is the key cultural dimension that is capable of explaining significant cultural differences between countries (Triandis 2001). 
More importantly, given the pandemic context of the study, focusing on IND/COL enables us to tap into people's behaviors in terms of how they will act as a group (or an individual) in response to using technology intended to mitigate pandemic spread. Additionally, a pandemic-like situation is managed directly by national governments and their public health institutes (e.g., the Centers for Disease Control and Prevention (CDC) in the United States). For example, the decisions to order lockdowns, make face coverings mandatory, and enforce social distancing are made by the national governments. In the same way, the decisions concerning the use of non-pharmaceutical technological intervention (NPTI) would have to be driven by the national governments (or state governments in some cases). We define NPTIs as technology-driven solutions that allow public health authorities to trace, track or monitor COVID-19 infected people and those who came in contact with them. The dimension of PD could explain the extent to which national governments could use their authority to mandate the use of NPTIs. Next, we briefly describe the two cultural dimensions, followed by a section on NPTIs that have been currently employed around the world.

\section{Power distance}

Inequality exists in all societies; however, some are more unequal than others (Geert Hofstede 2011). The cultural dimension of power distance highlights the extent to which individuals with less power in a society accept and expect an unequal distribution of power in society. In general, the common measures of inequality in society include the socioeconomic status of an individual, for example, their level of educational attainment, income, and profession. However, PD broadly captures inequality beyond socioeconomic characteristics. A fundamental trait of a high PD society is the expectation of obeying and/or showing deference to those perceived to have higher authority than oneself due to, for example, age, social affiliation, knowledge/expertise, and political and organizational ranks. In the same vein, employees working in high PD societies do not question their superiors even if they disagree; and the managers who ask their subordinates for feedback are considered weak and incompetent. By comparison, individuals in low PD societies are entitled to present their opinions regardless of others' perceived power or authority. Stated simply, PD is a measure of how individuals in society react to those in authority. In general, countries with high PD tend to be authoritarian such that those who do not comply may be punished, while countries with low PD value individuals' rights of their citizens.

\section{Individualism/collectivism}

IND/COL is a measure of whether individuals in a society are group-oriented versus selforiented. A self-oriented society is considered individualistic, while the one that is characterized by group-orientation is deemed collectivistic. Tajfel (1970) suggests a "we" versus "they" analogy to describe the difference between collectivism and individualism. "We" implies those who are perceived to be similar to self and are considered part of an individual's in-group, whereas "they" describes those who are outside of one's in-group. Collectivists or in-group members have shared goals, while individualists value autonomy. Collectivists have a strong sense of community, loyalty, respect, and trust towards the other members of their in-group. Individualists, by comparison, have loose ties with others and 
are universalistic in nature. They value their personal freedom and are not obligated to follow others in society (George et al. 2018). Though in this study, we apply IND-COL at a country-level, other examples of collectivist ingroups include a tribe, village, religious community, student body, and workgroup (Triandis 1996).

\section{Non pharmaceutical technological intervention (NPTI)}

The non-existence of any effective vaccine or definitive cure for COVID-19 has forced policymakers and healthcare authorities to focus on effective and innovative strategies to mitigate the COVID-19 pandemic using non-pharmaceutical interventions, such as social distancing, self-quarantine, self-isolation, and contact tracing. Practicing social distancing in both indoor and outdoor spaces, when it is possible, is playing an essential role in the spread of COVID-19, even if individuals do not have any symptoms. This is mainly due to the fact that people can spread the virus before they know they are sick or have any symptoms. Although the popular press articles tend to use quarantine and isolation interchangeably, it is important to mention the difference between the two. While quarantine keeps an individual who might have been exposed to the virus away from others, isolation is appropriate for someone who is confirmed infected with the virus (NCIRD 2020). Quarantine and isolation can occur at the individual's home, which we refer to as self-quarantine and self-isolation. People in self-quarantine and self-isolation should stay-at-home, separate themselves from other household members, and monitor their health for at least fourteen days (Lockerd Maragakis 2020). Contact tracing is a process that helps identify and inform who needs to self-quarantine. For example, an individual would need to be quarantined if he or she was within six feet of or had direct physical contact with an individual infected with the virus.

Countries around the world are embracing a variety of NPTIs to provide appropriate response efforts while monitoring the pandemic unfold with access to real-time data. In this study, we refer to these technologies or technology-mediated phenomena designed to curb the spread of COVID-19 as non-pharmaceutical technological interventions (NPTI). While organizations have been exploiting (big) data in novel ways to gain competitive advantage in the past few years (Gupta and George 2016), the use of individuals' public and private data by national governments was somewhat limited before COVID-19. Several countries are now taking advantage of NPTIs to track movements of individuals, especially those infected with the virus, others are utilizing NPTIs to enforce policies, such as mandatory quarantine or wearing face masks in public places. We next review the novel ways in which digital technologies have been used among different countries. Our review found that these technologies can be broadly categorized into types: (1) NPTIs for Contact Tracing and (2) NPTIs for Quarantine/Isolation.

\subsection{NPTIs for facilitating contact tracing}

Several countries have launched or plan to develop contact tracing mobile applications that use low-energy Bluetooth technology or location-tracking technology to trace people who have come in contact with confirmed COVID-19 positive patients. Countries such as Germany (Busvine 2020), Norway, Italy (Chabba 2020), Iceland (Svavarsdóttir 2020), South Korea (Fisher and Sang-Hun 2020), Singapore (Dick 2020), England (Kelion 2020), and Poland (Koper 2020) among others use these smartphone-enable applications (apps) to 
detect COVID-19's chain of contagion. These smartphone applications first identify the individuals who have come in contact with those tested positive with coronavirus and then send them notifications. Though there is near consensus in the potential of adopting these innovative technology solutions in mitigating the pandemic crisis, countries have different approaches to their implementation. In some countries, public health authorities encourage individuals to install the contact tracing app voluntarily; some countries mandate the use of tracking apps on individuals' cellphones, and those who are found in non-compliance can be fined and/or jailed (Lee et al. 2020).

For example, Germany has developed a smartphone application that uses low-energy Bluetooth technology based on a decentralized approach to trace infected patients' contacts. Germans would receive an emergency warning if they spent more than 15 minutes within six feet parameter of another app user who later tests positive. This application has high privacy features by encrypting the users' private information and making it impossible to identify users' identities. By promoting higher privacy and security design, the authorities encourage individuals to use it voluntarily (Busvine 2020).

Another example is France that has built its official contact tracing app "Stop COVID" with Bluetooth technology, and it is free to download for the users that are willing to install the app. However, it has received negative feedback due to concerns regarding its design and the possibility of users' privacy violations. It is mostly the result of French authorities decided to use the local centralized system. Its centralized database gives the government absolute control over the citizens' information and raises significant concerns regarding the government's misuse of this information for surveillance (Saget 2020).

\subsection{NPTIs for quarantine and self-isolation}

Once individuals who have been potentially exposed to COVID-19 are identified (i.e., using contact tracing), the next step is to either quarantine or isolate them. Specifically, the national governments and public health authorities are using NPTIs as methods of surveillance. For example, in China, the government runs a centralized mandatory mass surveillance program by integrating different facial recognition and social scoring systems (Altshuler and Hershkowitz 2020). Data are harvested through other channels from private companies such as Alibaba, Ant financial, and Tencent. Public or private, all the information collected should be made available to the Chinese authorities. Gathering information such as people's movement, travel history, credit card transactions, facial scans, and social media allows the Chinese government to enforce quarantine and self-isolation policies.

Beyond using facial recognition surveillance systems, the Chinese government has installed CCTV cameras at the entrance of apartments of patients to confirm their obeisance of fourteen-days quarantine policies. A QR code system sends signals to individuals to be aware of their status and if they are allowed to travel (Kharpal 2020). Similarly, in Vietnam, the ministry of health has launched a surveillance system to track patients' realtime movement under quarantine and self-isolation (Pollack et al. 2020).

In Hong Kong, the authorities enforce quarantine or self-isolation by making individuals wear a wristband, which sends a notification in the event of a breach in quarantine (Kharpal 2020). Moreover, all the travelers from overseas have to go on a fourteenday mandatory quarantine. Travelers must download an app called "StayHomeSafe," which works alongside the wearable device to detect any violations. An individual that violates this policy could receive $\$ 3200$ in fines and possibly up to six months of prison time (Huang et al. 2020b). Another example is Taiwan, where the government enforces 
quarantine and self-isolation using cellphone tracking, which is called "electronic fence" (BBC News 2020). Instead of asking users to download an app or a wearable tracking device, the surveillance system uses the individual's cellphone's GPS signals to locate the owner's location.

From the examples discussed thus far, it is clear that while countries have been making use of NPTIs in novel ways, there are differences in terms of how the use of these technologies has been made mandatory or voluntary. Moreover, people from different countries may likely react to the use of these government-controlled NPTIs differently (Blendon et al. 2006). We propose that these differences between countries in terms of how NPTIs should be implemented and how people from different countries would be receptive to or against using NPTIs for contact tracing and quarantine/isolation purposes is a function of the country's prevalent national culture. In the next section, we discuss the relationship between national culture and NPTIs use in detail.

\section{How national culture affects the success of NPTIs for pandemic mitigation?}

As discussed earlier, we specifically focus on two national cultural dimensions-PD and IND/COL. In addition to proposing the cultural dimensions, Hofstede et al. (2010) have proposed the country-level scores for PD and IND/COL. The scores range from 0 to 100. For PD, higher scores indicate a high power distance country. For IND/COL index, high values represent collectivism, while low scores imply a country is relatively individualistic. Utilizing these country-level scores, consistent with Hofstede et al. (2010), we create a $2 \times 2$ framework where the $\mathrm{X}$-axis represents individualism on the left and collectivism on the right side of the X-axis. The Y-axis on the top reflects high PD and the one on the bottom represents low PD. As shown in the Fig. 1, the intersection of the two axes creates four quadrants: (1) high power distance and collectivism, (2) high power distance and individualism, (3) low power distance and individualism, and (4) low power distance and collectivism.

In order to categorize countries into relative collectivist and individualist types and high PD and low PD types, Hofstede et al. (2010) have uses the cutoff value of 50. Thus, for IND/COL, the countries that score above 50 are considered comparatively collectivistic, while the ones that score below are individualistic. Those that score above 50 for PD are considered high PD countries, while those that score below are low PD societies. Table 1 lists the scores on IND/COL and PD for several countries that we use as examples in this study.

Next, we discuss each quadrant (Fig. 1) in detail, highlighting the impact of the intersection between IND/COL and PD cultural values on the NPTIs use for pandemic mitigation.

\section{Quadrant 1}

This quadrant lies at the intersection of high power distance and collectivistic cultural values. Examples of countries that fall into this quadrant include China, Singapore, South Korea, Vietnam, Taiwan, and India. We propose countries in this quadrant are best suited to take advantage of NPTIs. First, due to high PD values, governments in these countries can authoritatively enforce the use of NPTIs, expecting little to no 
Table 1 National scores for PD and IND/COL per Hofstede et al. (2010)

\begin{tabular}{lllll}
\hline Quadrant & Culture & Country & PD Score & COL Score \\
\hline 1 & High PD and COL & China & 80 & 80 \\
1 & High PD and COL & Singapore & 74 & 80 \\
1 & High PD and COL & Vietnam & 70 & 80 \\
1 & High PD and COL & Taiwan & 58 & 83 \\
1 & High PD and COL & Korea South & 60 & 82 \\
1 & High PD and COL & India & 77 & 52 \\
2 & High PD and IND & Poland & 68 & 40 \\
2 & High PD and IND & France & 68 & 29 \\
2 & High PD and IND & Belgium & 65 & 25 \\
2 & High PD and IND & Spain & 57 & 49 \\
3 & Low PD and IND & Germany & 35 & 33 \\
3 & Low PD and IND & Norway & 31 & 31 \\
3 & Low PD and IND & New Zealand & 22 & 21 \\
3 & Low PD and IND & United States & 40 & 9 \\
4 & Low PD and COL & Costa Rica & 35 & 85 \\
4 & Low PD and COL & Trinidad and Tobago & 47 & 84 \\
4 & Low PD and COL & Jamaica & 45 & 61 \\
\hline
\end{tabular}

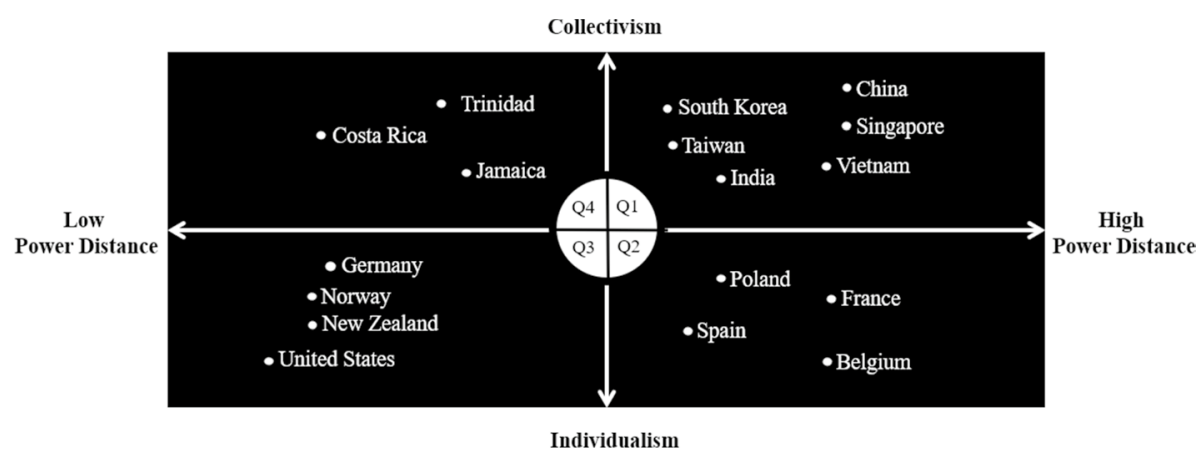

Fig. $12 \times 2$ Framework of countries based on the intersection of high and low levels of collectivism and power distance

resistance from people in general. As discussed earlier, several countries in this quadrant are exercising absolute authority in collecting all possible public and private data to ensure the adherence of health policy guidelines among the public. From using drones and CCTV cameras to surveil people to ordering individuals to wear wristbands, download apps on their cellphones, and allowing health authorities to connect with individuals' Bluetooth-enabled devices to track their movements in real-time is possible only because people in high PD countries are culturally tuned to accept that the governments have more power (or authority) than the individual. And that one should not revolt against the government. Another example is India, where in several states, the health authorities can access call detail records of COVID-positive individuals for the purpose 
of contact tracing (Times of India 2020). Moreover, those who do not provide the details could be reprimanded by the police. In sum, individuals in these countries do not have a choice, but to comply with NPTIs as mandated by their governments.

Second, in addition to having a high power distance culture, the countries in quadrant 1 are highly collectivistic. Not only does high PD values allow governments to be authoritative in this quadrant, but they will also find support among people to encourage others to participate in the government-run NPTIs initiatives. Collectivism endorses a sense of community among people in a country such that they tend to do things as a group. As such, in collectivistic cultures, the welfare of the group is more important than the self. Given the apparent benefits of utilizing NPTIs, people in collectivist cultures will be supportive of utilizing digital technologies to curb the spread of the pandemic. Individuals in these cultures are willing to give away their autonomy in order to protect their communities. Additionally, those who go against the community are likely to be punished by being boycotted by others in society.

As discussed earlier, Taiwan has implemented a system called "electronic fence" to track individuals' cellphones' GPS signals to locate their current location. If the cellphone goes off for more than fifteen minutes, an alarm would be sent to the authorities, and police officers would check those who are tracked to ensure compliance. In the case the individual cannot be tracked, he or she would be subject to $\$ 33,000$ in fines or getting arrested. While Taiwanese authorities could enforce such a system because of the country's high PD culture, it is interesting to note that there is widespread support from the public for this government-run surveillance system. As Lee et al. (2020) content, the Taiwanese approve the government's response with respect to using NPTIs as they believe this is a necessary sacrifice that the people need to make collectively to keep the country healthy and safe. In a similar fashion, the surveillance app launched by the Vietnamese authorities became the fourth most downloaded app in the health and fitness category on iOS devices, indicating overwhelming support from the public (Pollack et al. 2020).

Another example is South Korea that has successfully developed a set of strategies built on technological solutions such as patients' movement data based on GPS devices to track their contacts (Fisher and Sang-Hun 2020). Further, South Korean authorities have access to CCTV video recordings and credit card transactions to create a solution for tracing contacts of confirmed patients (Kharpal 2020). Although sharing such detailed information could violate an individual's privacy, South Koreans, given their collectivistic cultural values, have broadly trade off the loss of privacy as a necessary price to pay to gain public safety and well-being.

\section{Quadrant 2}

The quadrant 2 lies at the intersection of high power distance and individualistic cultural values. Examples of countries that fall into this quadrant include Poland, France, Spain, and Belgium. Unlike the countries in quadrant 1, where the use of NPTIs would be supported by the intersection of high PD and collectivistic cultures, the ones in this quadrant may still be able to exercise authority to enforce the use of NPTIs. However, the predominant individualism in these countries may make NPTIs use less effective than those in quadrant 1 . This is because individualism emphasizes self over the community. Thus, people in individualistic cultures do not have any incentive or an obligation to comply with 
what others in society are doing or suggesting. The lack of group orientation allows them to indulge in activities that are primarily relevant to themselves.

Nevertheless, an important aspect of the countries that fall into this quadrant is their high PD tendencies. High PD cultural values enable national governments to employ a top-down approach such that individuals will be expected to make use of technology the way authorities prescribe their use to mitigate the disease spread, regardless of whether there is widespread support for these initiatives or not. There will likely be some friction from inherent individualistic traits prevalent in these countries as individuals may feel their impression of independence has been compromised. However, the intrinsic acceptance of inequality in society does provide national governments an advantage to enforce NPTIs to a certain degree on masses as a pandemic mitigation tool.

The use of the "Stop COVID" contact tracing app in France is a good example where individuals have expressed concerns regarding the government having control over citizens' private data and more so storing these data on a centralized server. Yet, the French government has defended its decision, suggesting that by having centralized access; the app would help predict the areas where the next outbreak may happen. Similarly, Poland uses a COVID-tracking app called "ProteGo." The app serves as a self-health monitoring system that relies on the personal health data entered directly by the users. While the government claims that all user data remain anonymous, there have been worries that those with access to the centralized server could exploit data to determine individual identity (Gad-Nowak and Grzelak 2020).

Additionally, Poland utilizes an app called "Kwarantanna Domowa" (meaning "Home Quarantine" in Polish) that help public health authorities to impose mandatory quarantine at home (Squire Patton Boggs 2020). While this app was at first suggested for voluntary use, it has become compulsory overtime and "a tool to confirm compliance with quarantine obligations." It is not surprising, given Poland's high PD culture. Another example is from Antwerp, Belgium, where dockworkers are required to wear bracelets while they work (Meisenzahl 2020). If two workers come too close (i.e., less than five feet apart), the bracelets sound warnings.

These examples demonstrate that the national governments in the quadrant 2 countries, due to their high PD cultures, may still impose NPTIs use to a certain degree. However, due to the widespread individualism in their societies, the effect of collectivism on PD that was observed in quadrant 1 countries will likely be absent. In sum, the countries in this quadrant may still be able to utilize NPTIs, yet they should be mindful of the opposition against mandatory use of NPTIs.

\section{Quadrant 3}

This quadrant is characterized by low power distance and individualistic cultural values. Examples of countries in this quadrant include Germany, Norway, Italy and the United States. This quadrant is completely opposite of quadrant 1 . Low power distance cultural values promote equality in society such that the national government is considered for (and not above) the people. The presence of individualism enables people to do what they like without worrying about what others in society think of their choices. According to Hofstede et al. (2010), power distance and collectivism cultural values have a strong correlation (as shown in quadrant 1 and in this quadrant 3). However, as we discussed in quadrant 2, 
there are exceptions where some countries, despite having high power distance cultures could be individualistic.

While with high levels of PD and collectivistic cultural values, the countries in quadrant 1 are well-positioned to exploit NPTIs, the countries in quadrant 3 may find it challenging to impose the use of NPTIs, given their democratic governing style that values individual freedom and autonomy. That does not mean quadrant 3 countries would be unable to implement NPTIs for the purpose of pandemic mitigation; however, their use would likely be voluntary, and the data would be stored in a decentralized fashion to ensure individual identity is not compromised. The non-mandated voluntary use of NPTIs reflects the cultural values endorsed by the countries in quadrant 3 . Consequently, the effectiveness of NPTIs to curb the disease spread will be limited due to the lack of compulsion to engage with technological solutions designed to control the spread.

For example, despite the fact that Germany's contact tracing app is highly innovative and technologically superior to the ones developed by other countries, given its voluntary use, it can only be successful when there is widespread adoption of it by a large majority of Germans (Busvine 2020). Another example is Norway, which launched a "COVID-19 track and trace" app. The app was subsequently discontinued atter being criticized by the Norwegian Data Protection Authority (NDPA). The NDPA argued "collecting data through the app could no longer be seen as reasonable amid privacy concerns" (Reuters 2020). In Italy, although the government complies with the Pan-European Privacy-Preserving Proximity Tracing (PEPPT-PT) Consortium to address the privacy concerns of its citizens, only $12 \%$ of Italians aged between 14 and 75 years old installed the contact tracing app during the first six weeks (Giulio de Belvis et al. 2020). Due to Italy's low power distance and individualistic cultural values, the governing style emphasizes individual's freedom to use the app on a voluntary basis. However, these NPTIs require a higher adoption rate and use than $12 \%$ of the country's citizens to be effective. These cultural challenges undermine the potential benefits of NPTIs.

The U.S. is the epitome of individualism and low power distance society, Thus, it is highly libertarian when it comes to utilizing individual data by private companies (e.g., Amazon, Netflix, Apple, and Google) to create targeted ads or offer personalized recommendations to their users. However, the government authorities' use of these data is protected by law, and the authorities can only infringe on individuals' privacy if it is terrorism or crime-related (Kluth 2020). Given that there is no nationwide government-approved COVID-19 tracking app, despite COVID-19 being present in the U.S. for more than 6 months now and with the largest number of cases $(6.6$ million) and deaths $(196,810)$ in the world as of September 11, 2020, we do not foresee that there would be a COVID-19 contact tracing app in the future. The U.S. is an oddly interesting example; especially, when most of the world's technological innovations emerge in the Silicon Valley, a region in the State of California in the United States. This reflects that a country like the U.S. has the prowess to invent the most technologically advanced NPTIs for mitigating the pandemic spread; however, its culture acts as a deterrent to its successful implementation.

\section{Quadrant 4}

This quadrant is characterized by low power distance and collectivistic cultural values. According to Hofstede et al. (2010), Costa Rica, Trinidad and Tobago, and Jamaica are the only countries that fall into this quadrant. As such, of over 100 countries that have analyzed 
by cross-cultural scholars over the years, these are only select few countries that are collectivistic yet endorse low power distance cultural values.

Given the low PD cultural values, the countries in this quadrant will likely be unsuccessful in enforcing the mandatory use of NPTIs; however, they may still be able to employ technologies by emphasizing the sense of collectivism that is needed to curb the pandemic spread. As we know, people in collectivist cultures act as a group where the group success takes precedence over individual achievement. Therefore, the best approach is to highlight the advantages of using NPTIs to control the pandemic and how collectively people can keep their family and community safe.

Jamaica has launched an app called "JamCovid19" that enables Jamaicans to self-report their health status, book a COVID-19 testing appointment, and request emergency services (e.g., police or ambulance) if needed. Despite its limited features, the app allows Jamaicans to quickly identify if they need a COVID-19 test or hospital care. Instead of forcing every Jamaican download this app on their smartphones, an initiative that most likely would be unsuccessful given the country's low power distance culture; the government is emphasizing on collectivistic morals by asking people to participate in this initiative to "keep themselves and their loved ones informed" (The Office of the Prime Minister Jamaica 2020). In our review, we did not find specific examples of other countries in this quadrant using NPTIs; however, we are positive that there will likely be decent support from the communities in using NPTIs, given their collectivist cultural characteristics.

\section{Discussion}

The purpose of this paper was to theoretically examine the relationship between a nation's culture and NPTIs use for pandemic mitigation. We next discuss the theoretical and practical implications of this study, followed by study limitations and avenues for future research.

\subsection{Theoretical implications}

A major contribution of this study is that it underscores the significance of studying national cultures in understanding a number of business phenomena; especially the ones dealing with operations research and supply chain management (Zhang and Cao 2018; Durach and Wiengarten 2020). As Gupta and Gupta (2019; p. 2682) put it “... cross-cultural research in the $\mathrm{OM} / \mathrm{SCM}$ discipline remains scarce. Increased cross-cultural research is important for today's global supply chains in which manufacturers operate in multiple countries and interact with various international partners." Therefore, studying of national culture with respect to the role of technology is particularly important as the COVID-19 pandemic has not only caused a global health crisis, but it has also shocked the world economy. Our proposed $2 \times 2$ framework could further act as a guiding model for exploring a number of operations research constructs through the lens of national culture.

\subsection{Practical implications}

Our framework's main takeaway is that there is no one size fits all global approach concerning the use of NPTIs. Though most countries have the technological expertise and skills to develop NPTIs, it does not mean that their use could be easily mandated in all countries. Moreover, the extent to which people from different countries utilize NPTIs would 
significantly vary across countries. People in some countries may encourage everyone in their families and communities to help mitigate the pandemic spread by providing as much information as possible using NPTIs; however, people in other countries may find NPTIs use intrusive. Some countries could make NPTIs use compulsory, while others would have to make their use voluntary. What may work in China is unlikely to work in the U.S., for example. This study provides a culturally oriented explanation and guidance to government administrations and public health policy makers pertaining to employing NPTIs. The four quadrants describe the effect of the intersection of national cultural values of PD and IND/ COL on the success of utilizing NPTIs for containing a pandemic. Specifically, quadrant 1 countries, due to their high collectivism and power-distance-oriented cultural traits, are best suited to exploit NPTIs for controlling a COVID-19 type of pandemic, whereas quadrant 3 countries, given their low collectivism and power distance, would be less successful in utilizing NPTIs. Quadrant 2 and quadrant 4 countries, due to their high power distance and collectivism respectively, could still employ NPTIs to a certain degree to control and manage the disease outbreak.

\subsection{Limitations}

Like all research studies, this study has limitations, which offer interesting avenues for future research. While this study is an early attempt to highlight the importance of studying the efficacy of various NPTIs through the lens of country-level cultural differences, given that the study only focused on two cultural dimensions, we encourage future researchers to further theorize and empirically investigate the separate and bundled effects of other cultural dimensions, such as masculinity-femininity, uncertainty avoidance, long/short-term orientation, and indulgence-restraint. Another limitation of our work is its reliance on the Hofstede's cultural model. Therefore, future research could further explore the role of technology in mitigating pandemic through the lens of other established cross-cultural frameworks, such as high/low context cultural framework (Hall and Hall 1976), national cultural tightness-looseness (Gelfand et al. 2011), and the GLOBE (Global Leadership and Organizational Behavior Effectiveness) (House et al. 2002). Additionally, this study primarily focusses on NPTIs; however, other information communication technologies, such as Facebook and WhatsApp, could play a major role in informing (or rather ill-informing) people pertaining to the severity of the disease and the preventive measures (e.g., face coverings, hand sanitization, and social distancing) that may be needed in the absence of a cure or vaccine (Parra et al. 2021). Exploring the intersection of the role of national cultural values and individuals' use of online communities could yield interesting insights in understanding the spread of pandemic-related misinformation. Finally, we do not present our conceptual framework as absolute, and just like any theory, our model may have exceptions.

\section{References}

Akter, S., \& Wamba, S. F. (2019). Big data and disaster management: A systematic review and agenda for future research. Annals of Operations Research, 283(1-2), 939-959.

Altshuler, T. S., \& Hershkowitz, R. A. (2020). How Israel's COVID-19 mass surveillance operation works. https:/www.brookings.edu/techstream/how-israels-covid-19-mass-surveillance-operation-works/. Retrieved July 62020.

Anparasan, A., \& Lejeune, M. (2019). Resource deployment and donation allocation for epidemic outbreaks. Annals of Operations Research, 283(1), 9-32. 
Balcik, B., Beamon, B. M., Krejci, C. C., Muramatsu, K. M., \& Ramirez, M. (2010). Coordination in humanitarian relief chains: Practices, challenges and opportunities. International Journal of Production Economics, 126(1), 22-34.

Banomyong, R., Varadejsatitwong, P., \& Oloruntoba, R. (2019). A systematic review of humanitarian operations, humanitarian logistics and humanitarian supply chain performance literature 2005 to 2016. Annals of Operations Research, 283(1-2), 71-86.

Barro, R. J., Ursúa, J. F., \& Weng, J. (2020). The coronavirus and the great influenza pandemic: Lessons from the "Spanish Flu" for the coronavirus's potential effects on mortality and economic activity. National Bureau of Economic Research. https://doi.org/10.3386/w26866.

BBC News, B. N. (2020). Coronavirus: Under surveillance and confined at home in Taiwan. https:// www.bbc.com/news/technology-52017993. Retrieved March 242020.

Behl, A., \& Dutta, P. (2019). Humanitarian supply chain management: A thematic literature review and future directions of research. Annals of Operations Research, 283(1), 1001-1044.

Blendon, R. J., Des Roches, C. M., Cetron, M. S., Benson, J. M., Meinhardt, T., \& Pollard, W. (2006). Attitudes toward the use of quarantine in a public health emergency in four countries. Health Aff (Millwood), 25(2), w15-w25. https://doi.org/10.1377/hlthaff.25.w15.

Busvine, D. (2020). Explainer: Europe steps up tech battle vs. coronavirus with German app. https:// www.reuters.com/article/us-health-coronavirus-germany-app-explai/explainer-europe-steps-uptech-battle-vs-coronavirus-with-german-app-idUSKBN23M1HM. Retrieved JUNE 152020.

Çankaya, E., Ekici, A., \& Özener, O. (2019). Humanitarian relief supplies distribution: An application of inventory routing problem. Annals of Operations Research, 283(1-2), 119-141.

CDC (2020). Social Distancing. https://www.cdc.gov/coronavirus/2019-ncov/prevent-getting-sick/socia 1-distancing.html. Retrieved June 102020.

Chabba, S. (2020). Coronavirus tracking apps: How are countries monitoring infections? https://www. dw.com/en/coronavirus-tracking-apps-how-are-countries-monitoring-infections/a-53254234. Retrieved April 272020.

Dahab, M., van Zandvoort, K., Flasche, S., Warsame, A., Ratnayake, R., Favas, C., et al. (2020). COVID-19 control in low-income settings and displaced populations: what can realistically be done? Conflict Health, 14, 54. https://doi.org/10.1186/s13031-020-00296-8.

Davis, F. D. (1989). Perceived usefulness, perceived ease of use, and user acceptance of information technology. MIS Quarterly, 13, 319-340.

Dick, S. (2020). Singapore's coronavirus temperature scans and tracking leading the way. https://thene wdaily.com.au/news/national/2020/03/19/singapore-coronavirus-temperature-scans/. Retrieved Mar 192020.

Doney, P. M., Cannon, J. P., \& Mullen, M. R. (1998). Understanding the influence of national culture on the development of trust. Academy of Management Review, 23(3), 601-620.

Dubey, R., Bryde, D. J., Foropon, C., Graham, G., Giannakis, M., \& Mishra, D. B. (2020a). Agility in humanitarian supply chain: An organizational information processing perspective and relational view. Annals of Operations Research, 1-21.

Dubey, R., Bryde, D. J., Foropon, C., Tiwari, M., Dwivedi, Y., \& Schiffling, S. (2020b). An investigation of information alignment and collaboration as complements to supply chain agility in humanitarian supply chain. International Journal of Production Research, 1-20.

Dubey, R., Gunasekaran, A., \& Papadopoulos, T. (2019). Disaster relief operations: Past, present and future. Annals of Operations Research, 283(1-2), 1-8.

Durach, C. F., \& Wiengarten, F. (2020). Supply chain integration and national collectivism. International Journal of Production Economics, 224, 107543.

Earley, P. C., \& Ang, S. (2003). Cultural intelligence: Individual interactions across cultures. Stanford: Stanford University Press.

Fisher, M., \& Sang-Hun, C. (2020). How South Korea Flattened the Curve. https://www.nytim es.com/2020/03/23/world/asia/coronavirus-south-korea-flatten-curve.html. Retrieved March 23 2020.

Gad-Nowak, M., \& Grzelak, M. (2020). COVID-19: Poland launches an official tracking app. https:// www.ceelegalblog.com/2020/04/covid-19-poland-launches-an-official-tracking-app/. Retrieved April 242020.

Gelfand, M. J., Raver, J. L., Nishii, L., Leslie, L. M., Lun, J., Lim, B. C., et al. (2011). Differences between tight and loose cultures: A 33-nation study. Science, 332(6033), 1100-1104.

George, J. F., Gupta, M., Giordano, G., Mills, A. M., Tennant, V. M., \& Lewis, C. C. (2018). The effects of communication media and culture on deception detection accuracy. MIS Quarterly, 42(2), 551-575.

Giulio de Belvis, A., Fattore, G., Morsella, A., Pastorino, G., Poscia, A., Ricciardi, W., et al. (2020). COVID-19 HEalth System Response Monitor - Policy Responses for Italy. https://www.covid 
19healthsystem.org/countries/italy/livinghit.aspx?Section=1.4\%20Monitoring\%20and\%20surveill ance $\&$ Type $=$ Section. Retrieved August 272020.

Gupta, M., Esmaeilzadeh, P., Uz, I., \& Tennant, V. M. (2019). The effects of national cultural values on individuals' intention to participate in peer-to-peer sharing economy. Journal of Business Research, 97, 20-29.

Gupta, M., \& George, J. F. (2016). Toward the development of a big data analytics capability. Information and Management, 53, 1049-1064.

Gupta, M., \& Gupta, S. (2019). Influence of national cultures on operations management and supply chain management practices-A research agenda. Production and Operations Management, 26, 2681-2698.

Gupta, M., Uz, I., Esmaeilzadeh, P., Noboa, F., Mahrous, A. A., Kim, E., et al. (2018). Do cultural norms affect social network behavior inappropriateness? A global study. Journal of Business Research, 85, $10-22$.

Hall, E. T., \& Hall, E. (1976). How cultures collide. Psychology Today, 10(2), 66-97.

Hill, C. W. L. (2005). International business: Competing in the global marketplace (Vol. 5). New York: McGraw-Hill.

Hofstede, G. (1980). Culture's consequences: International differences in work-related values (Vol. 5). London: Sage Publications.

Hofstede, G. (2011). Dimensionalizing cultures: The Hofstede model in context. Online readings in psychology and culture, $2(1), 8$.

Hofstede, G., \& Bond, M. H. (1988). The Confucius connection: From cultural roots to economic growth. Organizational Dynamics, 16(4), 5-21.

Hofstede, G., Hofstede, G. J., \& Minkov, M. (2010). Cultures and organizations: Software of the mind. Revised and expanded. New York: McGraw-Hill.

House, R., Javidan, M., Hanges, P., \& Dorfman, P. (2002). Understanding cultures and implicit leadership theories across the globe: An introduction to project GLOBE. Journal of World Business, $37(1), 3-10$.

House, R. J., Hanges, P. J., Javidan, M., Dorfman, P. W., \& Gupta, V. (2004). Culture, leadership, and organizations: The GLOBE study of 62 societies. London: Sage publications.

Huang, C., Wang, Y., Li, X., Ren, L., Zhao, J., Hu, Y., et al. (2020). Clinical features of patients infected with 2019 novel coronavirus in Wuhan, China. The lancet, 395(10223), 497-506.

Huang, Y., Sun, M., \& Sui, Y. (2020). How Digital Contact Tracing Slowed Covid-19 in East Asia. https ://hbr.org/2020/04/how-digital-contact-tracing-slowed-covid-19-in-east-asia.

Ivanov, D., \& Dolgui, A. (2020a). OR-methods for coping with the ripple effect in supply chains during COVID-19 pandemic: Managerial insights and research implications. International Journal of Production Economics, 107921.

Ivanov, D., \& Dolgui, A. (2020b). Viability of intertwined supply networks: extending the supply chain resilience angles towards survivability. A position paper motivated by COVID-19 outbreak. International Journal of Production Research, 58(10), 2904-2915.

Jabbour, C. J. C., Janeiro, R. C., de Sousa Jabbour, A. B. L., Junior, J. A. G., Salgado, M. H., \& Jugend, D. (2020). Social aspects of sustainable supply chains: Unveiling potential relationships in the Brazilian context. Annals of Operations Research, 290(1), 327-341.

Kelion, L. (2020). Coronavirus: England's contact-tracing app gets green light for trial. https://www.bbc. com/news/technology-53753678. Retrieved August 122020.

Kharpal, A. (2020). Use of surveillance to fight coronavirus raises concerns about government power after pandemic ends. https://www.cnbc.com/2020/03/27/coronavirus-surveillance-used-by-gover nments-to-fight-pandemic-privacy-concerns.html. Retrieved March 262020.

Kluth, A. (2020). If we must build a surveillance state, let's do it properly. https://www.bloomberg.com/ opinion/articles/2020-04-22/taiwan-offers-the-best-model-for-coronavirus-data-tracking. Retrieved April 222020.

Koper, A. (2020). Poland rolls out privacy-secure coronavirus tracking app. https://www.usnews.com/ news/technology/articles/2020-06-09/poland-rolls-out-privacy-secure-coronavirus-tracking-app. Retrieved June 92020.

Kroeber, A. L., Kluckhohn, C., Untereiner, W., \& Meyer, A. G. (1952). Culture: A critical review of concepts and definitions. New York: Vintage Books.

Lee, W.-Y., McCauley, E., \& Abadi, M. (2020). Taiwan used police surveillance, government tracking, and $\$ 33,000$ fines to contain its coronavirus outbreak. https://www.businessinsider.com/taiwa n-coronavirus-surveillance-masks-china-2020-6. Retrieved Jun 42020. 
Lockerd Maragakis, L. (2020). Coronavirus, social and physical distancing and self-quarantine. https ://www.hopkinsmedicine.org/health/conditions-and-diseases/coronavirus/coronavirus-social-dista ncing-and-self-quarantine. Retrieved April 152020.

Meisenzahl, M. (2020). Dock workers in Belgium are wearing monitoring bracelets that enforce social distancing-here's how they work. https://www.businessinsider.com/workers-in-belgium-use-socia 1-distancing-wearable-tech-2020-5. Retrieved May 92020.

Metters, R., Zhao, X., Bendoly, E., Jiang, B., \& Young, S. (2010). The way that can be told of is not an unvarying way": Cultural impacts on Operations Management in Asia. Journal of Operations Management, 28(3), 177-185. https://doi.org/10.1016/j.jom.2009.10.004.

Morath, E., \& Chaney, S. (2020). U.S. Jobless Claims Top 20 Million Since Start of Shutdowns. https:// www.wsj.com/articles/u-s-unemployment-claims-likely-continued-at-record-levels-11587029401. Retrieved April 162020.

NCIRD, N. C. F. I. A. R. D. D. O. V. D. (2020). When to Quarantine-Stay home if you might have been exposed to COVID-19. https://www.cdc.gov/coronavirus/2019-ncov/if-you-are-sick/quarantine .html. Retrieved August 162020.

Parra, C. M., Gupta, M., \& Mikalef, P. (2021). Information and communication technologies (ICT)enabled severe moral communities and how the (Covid19) pandemic might bring new ones. International Journal of Information Management, 57, 102271.

Pollack, T., Thwaites, G., Rabaa, M., Choisy, M., van Doorn, R., Luong, D. H., et al. (2020). Emerging COVID-19 success story: Vietnam's commitment to containment. https://ourworldindata.org/covid -exemplar-vietnam. Retrieved June 30, 20202020.

Queiroz, M. M., Ivanov, D., Dolgui, A., \& Wamba, S. F. (2020). Impacts of epidemic outbreaks on supply chains: mapping a research agenda amid the COVID-19 pandemic through a structured literature review. Annals of Operations Research, 1-38.

Reuters. (2020). Norway to halt COVID-19 track and trace app on data protection concerns. https:// www.reuters.com/article/us-health-coronavirus-norway-apps/norway-to-halt-covid-19-track-andtrace-app-on-data-protection-concerns-idUSKBN23M18T. Retrieved June 152020.

Saget, J. (2020). France rolls out Covid-19 tracing app amid privacy debate. https://www.france24.com/ en/20200602-france-rolls-out-covid-19-tracing-app-amid-privacy-debate. Retrieved February 06 2020.

Squire Patton Boggs. (2020). COVID-19: Poland Launches an Official Tracking App. https://www.natla wreview.com/article/covid-19-poland-launches-official-tracking-app. Retrieved September 122020.

Srite, M., \& Karahanna, E. (2006). The role of espoused national cultural values in technology acceptance. MIS Quarterly, 30(3), 679-704.

Svavarsdóttir, S. (2020). Controlling and preventing infection spread in Iceland. https://www.healtheuro pa.eu/controlling-and-preventing-infection-spread-in-iceland/101614/. Retrieved July 232020.

Tajfel, H. (1970). Experiments in intergroup discrimination. Scientific American, 223(5), 96-102.

The Office of the Prime Minister Jamaica. (2020). JamCOVID App Now Available for Download on Android Devices. https://jis.gov.jm/jamcovid-app-now-available-for-download-on-android-devic es/. Retrieved May 142020.

Times of India, T. (2020). At least 8 states using CDRs to track patients. https://timesofindia.indiatimes .com/india/at-least-8-states-using-cdrs-to-track-patients/articleshow/77644710.cms. Retrieved August 202020.

Triandis, H. C. (1996). The psychological measurement of cultural syndromes. American Psychologist, $51(4), 407$.

Triandis, H. C. (2001). Individualism-collectivism and personality. Journal of Personality, 69(6), 907924. https://doi.org/10.1111/1467-6494.696169.

Truelove, S., Abrahim, O., Altare, C., Lauer, S. A., Grantz, K. H., Azman, A. S., et al. (2020). The potential impact of COVID-19 in refugee camps in Bangladesh and beyond: A modeling study. PLoS Med, 17(6), e1003144. https://doi.org/10.1371/journal.pmed.1003144.

Venkatesh, V., Thong, J. Y., \& Xu, X. (2012). Consumer acceptance and use of information technology: extending the unified theory of acceptance and use of technology. MIS Quarterly, 36(1), 157-178.

Walker, P., Whittaker, C., Watson, O., Baguelin, M., Ainslie, K., Bhatia, S., et al. (2020). Report 12: The global impact of COVID-19 and strategies for mitigation and suppression. School of Public Health Imperial College London COVID-19. doi:https://doi.org/10.25561/77735.

Whitelaw, S., Mamas, M. A., Topol, E., \& Van Spall, H. G. C. (2020). Applications of digital technology in COVID-19 pandemic planning and response. The Lancet Digital Health, 2(8), e435-e440. https ://doi.org/10.1016/s2589-7500(20)30142-4.

WHO, T. W. H. O. (2020). WHO Director-General's opening remarks at the media briefing on COVID19, 11 March 2020. Geneva, Switzerland. 
Zhang, Q., \& Cao, M. (2018). Exploring antecedents of supply chain collaboration: Effects of culture and interorganizational system appropriation. International Journal of Production Economics, 195, $146-157$.

Zhu, N., Zhang, D., Wang, W., Li, X., Yang, B., Song, J., et al. (2020). A novel coronavirus from patients with pneumonia in China, 2019. New England Journal of Medicine, 382, 727-733.

Publisher's note Springer Nature remains neutral with regard to jurisdictional claims in published maps and institutional affiliations. 